\title{
Modelling of Post-flotation Tailings Liquefaction Induced by Paraseismic Events
}

\author{
Waldemar Świdziński \\ Institute of Hydro-Engineering, Polish Academy of Sciences, Kościerska 7, 80-328 Gdańsk, Poland, \\ e-mail: waldek@ibwpan.gda.pl
}

(Received December 5, 2016; revised January 16, 2017)

To the memory of Andrzej Sawicki, my PhD Promotor, long-standing mentor, colleague and boss

\begin{abstract}
This paper presents and discusses the results of numerical modelling of pore water pressure build-up in post-flotation saturated tailings deposited at the Tailings Storage Facility "ZZelazny Most", caused by seismic-induced dynamic loading. Numerical simulations were based on the compaction/liquefaction model proposed by A. Sawicki. The model parameters were determined in the laboratory for tailings sampled at the TSF "Żelazny Most". The sensitivity of the numerical model was verified in a series of numerical tests for various horizontal acceleration amplitudes. In the main calculations, an accelerogram recorded during a real paraseimic event was assumed. The results obtained show that, with the current seismic activity near the TSF "Żelazny Most", some pore water pressure is generated within the saturated tailings layer, but it does not trigger the liquefaction phenomenon.
\end{abstract}

Key words: post-flotation tailings, cyclic loading, liquefaction, modelling

\section{Introduction}

One of basic features of copper production is a huge amount of tailings resulting from the crashing, milling and flotation of copper ore. They may constitute more than $99 \%$ of total exploited rock. The standard method of utilizing these tailings is to deposit them as wet material at tailings storage facilities (TSFs), which for economic reasons are located near the mines. The tailings are usually deposited by the so-called spigotting method in the form of wet slurry discharged circumferentially from the crest of dams constraining the facility. From geotechnical point of view, post-flotation tailings correspond to silty sands with some admixture of clays, in which the sandy fraction may vary from $70 \%$ up to $90 \%$ (Świdziński 2011). Discharged saturated tailings undergo a natural process of gravitational segregation, during which coarser fractions deposit near the dam crest, whereas finer ones, in the form of slimes, are transported 
inwards by water. Thus tailings may be in a loose state, and due to the subsequent deposition of new portions, a large mass of them is fully saturated. All of the above creates almost perfect conditions predisposing a soil to liquefaction. Such a phenomenon occurs when, due to adverse loading conditions (static or dynamic ones) causing pore water pressure generation, there is a considerable decrease in effective stresses, down to the residual shear strength.

Such adverse loading conditions can occur when a mass of saturated tailings is subjected to seismic waves induced by mine rockbursts, which is quite often the case when the facilities are located near mines. Since mine rockbursts are man-made effects, they are often called paraseismic events to distinguish them from natural earthquakes. Such events are usually of relatively short duration, during which the generated pore water pressure has practically no time to dissipate, which creates undrained conditions that may lead to the liquefaction of tailings.

Liquefaction is mostly observed in sandy soils, but the results of comprehensive investigations carried out in the last decades have shown that sands containing some portion of a fine fraction may liquefy as well (Yamamuro and Covert 2001, Boulanger and Idriss 2006).

The results of laboratory tests performed on samples of tailings taken from the TSF “Żelazny Most” KGHM POLSKA MIEDŹ, indicate that such material may be even more prone to liquefaction than typical sand (Świdziński 2011).

There exist some empirical methods for assessing the liquefaction potential of saturated non-cohesive soils, see e.g. (Seed and Idriss 1970, PIANC 2001), but just few approaches have been addressed to solve this problem on the basis of theoretical models. One of them is a model originally developed by A. Sawicki (1987).

This paper presents the results of numerical simulations of pore water generation in a tailings mass subjected to dynamic loading caused by a paraseismic event. For the numerical analyses, the compaction/liquefaction $(\mathrm{C} / \mathrm{L})$ model proposed by Sawicki (1987) was adapted to the conditions of the TSF "Żelazny Most". In the past, the $\mathrm{C} / \mathrm{L}$ model has been applied to numerous boundary value problems corresponding to various engineering issues related to the cyclic response of saturated sands in undrained conditions, see e.g. (Sawicki and Świdziński 1989, 2007, Przewłócki and Knabe 1995, Sawicki 2004). The model parameters were determined for samples of tailings taken from the facility. The model was adapted to the 1D problem of a layer of saturated tailings subjected to cyclic loading. The sensitivity of the model was verified by a series of numerical tests for various values of the horizontal acceleration amplitude. The main calculations were performed for a cyclic loading corresponding to an accelerogram caused by a real paraseismic event recorded near the facility.

\section{Compaction/Liquefaction Model}

The C/L model, elaborated by Prof. A. Sawicki in the 1980s, has been presented in many papers. Therefore, for the present purpose, it will be described only very briefly. 
The $\mathrm{C} / \mathrm{L}$ model is characterised by three constitutive equations:

a) a compaction law describing the compaction of a dry non-cohesive soil due to cyclic shearing:

$$
\frac{d \Phi}{d N}=\frac{1}{4} D_{1} \gamma_{0}^{2} \exp \left(-D_{2} \Phi\right)
$$

where $\Phi$ is a compaction function related to the volumetric strain of the soil $\varepsilon_{v}$ by the following formula:

$$
\Phi=\frac{1-n_{0}}{n_{0}} \varepsilon_{v},
$$

where: $n_{0}$ - initial porosity, $D_{1}, D_{2}$ - material constants describing the compactness of a given non-cohesive soil, which have to be determined experimentally, $J$ - the second invariant of the strain amplitudes deviator $\breve{E}^{\mathrm{dev}}$, which in the general case can be written as

$$
J=\frac{1}{2} \operatorname{tr}\left(\check{E}^{\operatorname{dev}}\right)^{2} .
$$

It should be noted that the $\mathrm{C} / \mathrm{L}$ model is a so-called average engineering model (Sawicki 1987), since it does not take into account the full history of cyclic loading within a given cycle, but only its amplitude (the maximum magnitude above the equilibrium state).

b) the stress-strain linear relationship between stress $\left(\check{T}^{\text {dev }}\right)$ and strain $\left(\check{E}^{\text {dev }}\right)$ amplitude deviators:

$$
\check{T}^{\mathrm{dev}}=2 G \check{E}^{\mathrm{dev}},
$$

where $G$ is the shear modulus related to the mean effective stress by the following relation:

$$
G=G_{0}+G_{1} \sqrt{p^{\prime}} .
$$

where: $G_{0}, G_{1}$ - coefficients which have to be determined experimentally for a given soil.

The coefficient $G_{0}$ corresponds to a residual shear modulus of liquefied soil ( $p^{\prime}=$ $0 \mathrm{kPa}$ ), and independently it plays an important role in numerical calculations, making it possible to continue the calculation process when liquefaction occurs at some model point.

Equations (1)-(4) serve to describe volume changes in a dry non-cohesive soil caused by cyclic shearing for a given strain or stress history.

c) an equation relating volumetric changes in a dry non-cohesive soil to the equivalent generation of pore water pressure $u$ for a saturated soil in undrained conditions:

$$
\frac{d u}{d N}=\frac{1}{a} \frac{d \Phi}{d N}
$$




$$
a=\frac{1-n_{0}}{n_{0}} \kappa_{s},
$$

where $\kappa_{s}$ is an elastic constant describing the elastic compressibility of a dry non-cohesive soil, which may also be expressed by two other independent elastic constants i.e. Young's modulus $E$ and Poisson's ratio $v$ as $\kappa_{s}=3(1-2 v) / E$.

Equations (1), (4) and (6) make it possible to calculate the generation of pore water pressure in a non-cohesive soil subjected to cyclic shearing in undrained conditions until its total liquefaction, described by the following condition:

$$
p^{\prime}=p_{0}^{\prime}-u=0,
$$

where $p_{0}^{\prime}$ is the initial mean effective stress prior to cyclic loading.

For the sake of convenience, in this model, stress is expressed in $10^{5} \mathrm{~N} / \mathrm{m}^{2}$ and strain in $10^{-3}$.

\section{Determination of Model Parameters}

Model parameters were determined for tailings sampled from one of geotechnical cross-sections running perpendicular to the southern dam of the TSF “Żelazny Most", at a distance of $300 \mathrm{~m}$ from the dam crest and at a depth of $1 \mathrm{~m}$. The tailings at such a distance contain a considerable portion of fine fraction corresponding to a relatively low value of SFR $=2.85$. Therefore, it was assumed that such tailings are the most representative to model pore water pressure generation. Furthermore, at such a distance, the line of full saturation is located at a quite shallow depth. The index properties of the tailings material assumed in numerical simulations are collated in Table 1 (Świdziński 2011).

Table 1. Index properties of tailings taken from the TSF "Żelazny Most" at a distance of 300 $m$ from the dam crest

\begin{tabular}{|c|c|c|c|c|c|c|c|c|c|}
\hline$w_{n}$ & $\rho_{s}$ & $\rho_{\max }$ & $\rho_{\min }$ & $e_{\max }$ & $e_{\min }$ & $d_{50}$ & $d_{10}$ & $d<0.075 \mathrm{~mm}$ & SFR \\
\hline$[\%]$ & {$\left[\mathrm{g} / \mathrm{cm}^{3}\right]$} & {$\left[\mathrm{g} / \mathrm{cm}^{3}\right]$} & {$\left[\mathrm{g} / \mathrm{cm}^{3}\right]$} & {$[-]$} & {$[-]$} & {$[\mathrm{mm}]$} & {$[\mathrm{mm}]$} & {$[\%]$} & {$[-]$} \\
\hline 7.96 & 2.68 & 1.62 & 1.17 & 1.284 & 0.656 & 0.090 & 0.032 & 26.0 & 2.85 \\
\hline
\end{tabular}

\subsection{Common Compaction Curve}

The consequence of the compaction law given by Eq. (1) is the hypothesis that, for a given non-cohesive soil subjected to cyclic loading, there exists one unique common compaction curve characterising the compactness of this soil. This idea combines various compaction curves, which represent the compaction response to various shear strain amplitudes as a function of loading cycles, in one single compaction curve as a function of a new model variable.

Such a curve for dry non-cohesive soils can be determined experimentally using the cyclic simple shear apparatus. The results of tests in the form of soil compaction 
versus the number of loading cycles can be approximated by the compaction function from Eq. (1), which makes it possible to determine model parameters $D_{1}, D_{2}$ for the soil tested. Numerous investigations carried out on various types of non-cohesive soils have confirmed the existence of such a curve, however for a range of loading cycles limited to several hundreds, only, see (Sawicki and Świdziński 1989, 2007, Świdziński 2006). Considering that the model is used to describe the response of soil subjected to an earthquake whose duration corresponds to approximately one hundred cycles, the application of the model to that case is fully justified.

The tests on samples of tailings with some admixture of silts were carried out with a cyclic simple shear apparatus designed and constructed at the Geotechnical Laboratory IBW PAN (Świdziński 2006). The samples were reconstituted within the apparatus as a dry material to the assumed density and then subjected to cyclic shearing at four different shear strain amplitudes $\gamma_{0} \approx 1,2,3$ and $4 \times 10^{-3}$, and at a constant mean effective stress of $100 \mathrm{kPa}$. Real amplitude values differed slightly from the assumed ones because of the accuracy of the amplitude setter as well as its small change in the course of soil compaction. Four series of tests were performed for each amplitude. The cyclic loading wave had a sinusoidal shape of $f=0.5 \mathrm{~Hz}$ frequency, and the samples were subjected to 50 loading cycles. During each test, the settlement of the sample versus the number of loading cycles was recorded.

The results of 12 tests are presented in Fig. 1 as the compaction of a given sample under a given shear strain amplitude versus the number of loading cycles.

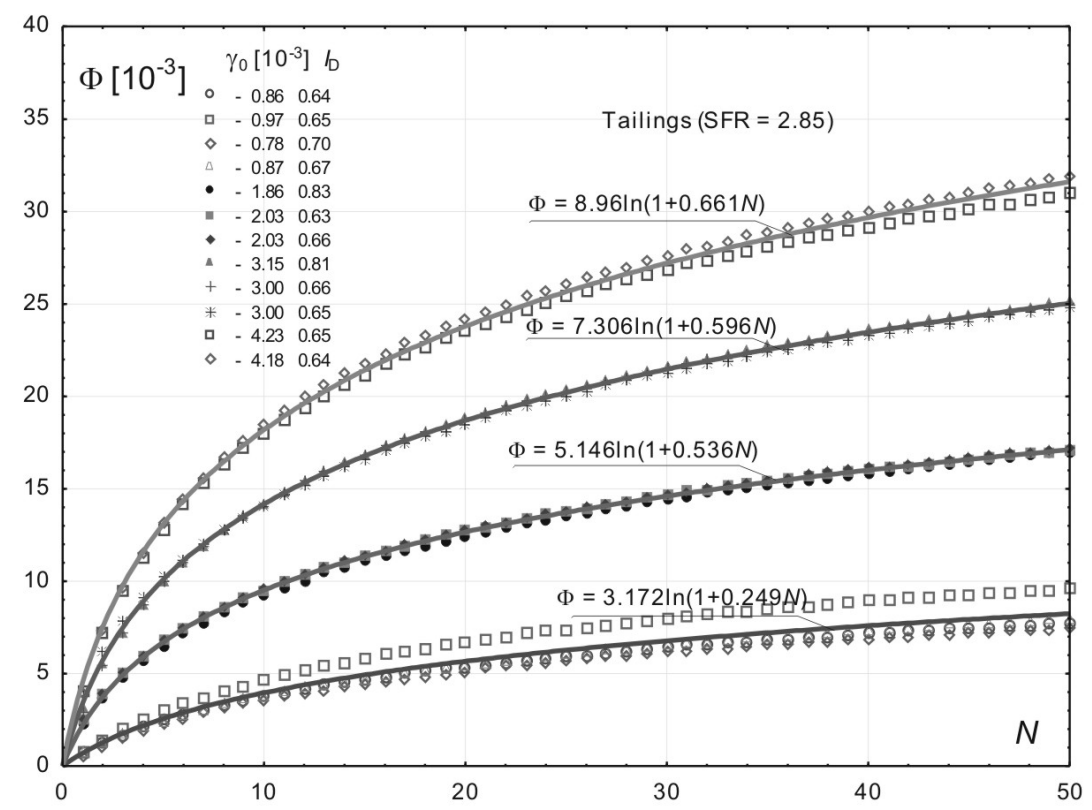

Fig. 1. Compaction of tailings due to cyclic simple shear at various shear strain amplitudes 
For each series corresponding to the same shear strain amplitude, the soil response in the form of compaction is very similar and can be nicely approximated by a logarithmic function:

$$
\Phi=B_{1} \ln \left(1+B_{2} N\right),
$$

where $B_{1}$ and $B_{2}$ are coefficients which can easily be determined by standard optimization methods.

For the case of cyclic simple shearing at the constant shear strain amplitude $\gamma_{0}$, the general relation for the second invariant of the strain deviator given by Eq. (3) can be written as

$$
J=\frac{1}{4} \gamma_{0}^{2}
$$

In terms of a formal transformation of Eq. (1), under the assumption that the compaction function $\Phi$ can be described by a logarithmic function similar to that given by Eq. (9), we obtain

$$
\Phi=C_{1} \ln \left(1+C_{2} \xi\right),
$$

where the new model variable $\xi$ is described by the following formula:

$$
\xi=J N=\frac{1}{4} \gamma_{0}^{2} N
$$

The coefficients $C_{1}$ and $C_{2}$ are related to the coefficients $D_{1}$ and $D_{2}$ occurring in the compaction law (1) (Sawicki 1987), by the following relations:

$$
D_{1}=C_{1} C_{2}, D_{2}=\frac{1}{C_{1}} \text {. }
$$

Fig. 2 presents the results from Fig. 1 in the new interpretation $\Phi-\xi$.

According to Fig. 2, the data lying along various curves in Fig. 1, can be represented in a new configuration by a single curve called the common compaction curve. This curve can be nicely approximated by the logarithmic function prescribed by Eq. (11).

The values of the coefficients $C_{1}$ and $C_{2}$ are 7.313 and 0.244 , respectively, with a mean standard deviation of 0.71 . Please note that these values correspond to the specific units assumed, where the variable $\xi$ is expressed in $10^{-6}$ and the compaction function $\Phi$ in $10^{-3}$, see Section 2. The calculated values of $D_{1}$ and $D_{2}$ are 1.784 and 4.098 , respectively.

\subsection{Determination of Shear Modulus as a Function of Mean Effective Stress}

The dependence between shear modulus and mean effective stress described by Eq.

(5) was determined for undisturbed samples taken from the tailings deposits at the TSF “Żelazny Most”. The samples were tested in a triaxial apparatus equipped with a pair of bender elements, which makes it possible to determine the maximum shear 


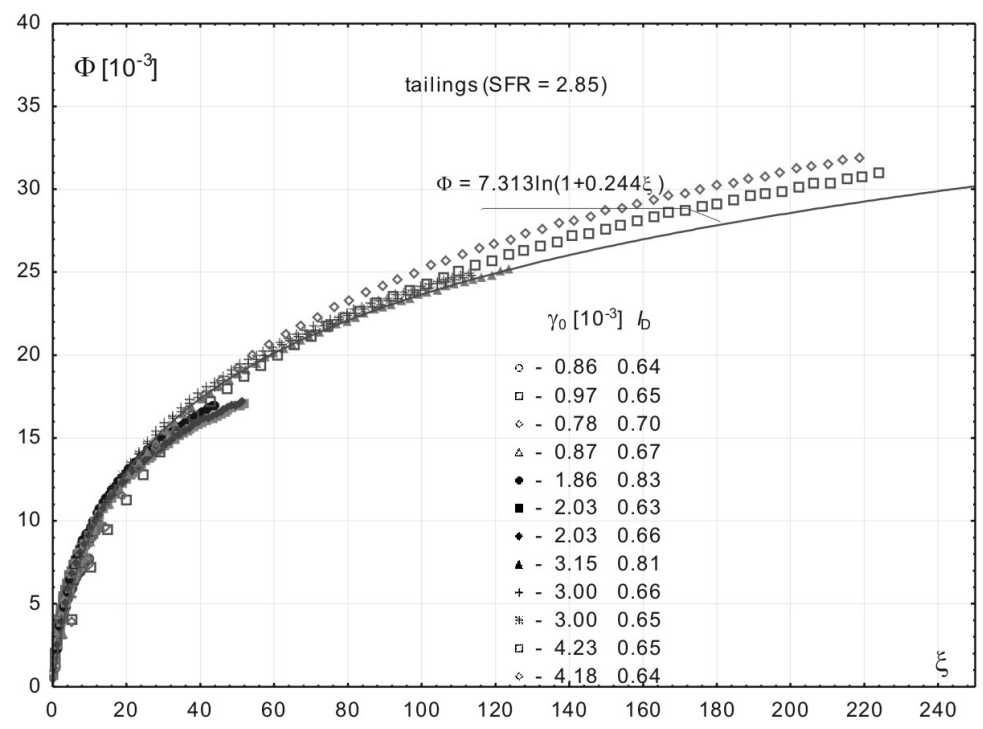

Fig. 2. Common compaction curve interpreted on the basis of results shown in Fig. 1

modulus within a range of very small strains of $10^{-6}$ based on the measurement of the S-wave velocity, see e.g. (Świdziński and Mierczyński 2010). The maximum shear modulus determined in this way corresponds to the elastic response of the soil.

According to the theory of wave propagation in an isotropic elastic uniform medium, the shear wave velocity is proportional to the stiffness of the material and inversely proportional to its density, Dyvic and Madhus (1985):

$$
v_{S}=\sqrt{\frac{G_{\max }}{\rho}} .
$$

Knowing the velocity of the shear wave and the density of the material tested, one can easily determine $G_{\max }$. The tests were carried out for undisturbed samples of tailings taken at distances of 40,120 and $200 \mathrm{~m}$ from the dam crest at various levels of the mean effective stress equal to 67, 133, 267, 367, 537 and $667 \mathrm{kPa}$ (Świdziński and Mierczyński 2012). The results of the test are presented in Fig. 3.

The results were approximated by relation (5), and the values of the coefficients $G_{0}$ and $G_{1}$ are 0.0283 and 0.8876 , respectively. It should be noted that the coefficients are in the modulus unit i.e. $10^{8} \mathrm{~N} / \mathrm{m}^{2}$.

\section{Assessment of Liquefaction Potential for a Mass of Saturated Tailings}

An assessment of the liquefaction potential of a mass of saturated tailings subjected to cyclic loading induced by a paraseismic event was carried out for a real engineering case based on conditions corresponding to those existing at the TSF "Z̈elazny 


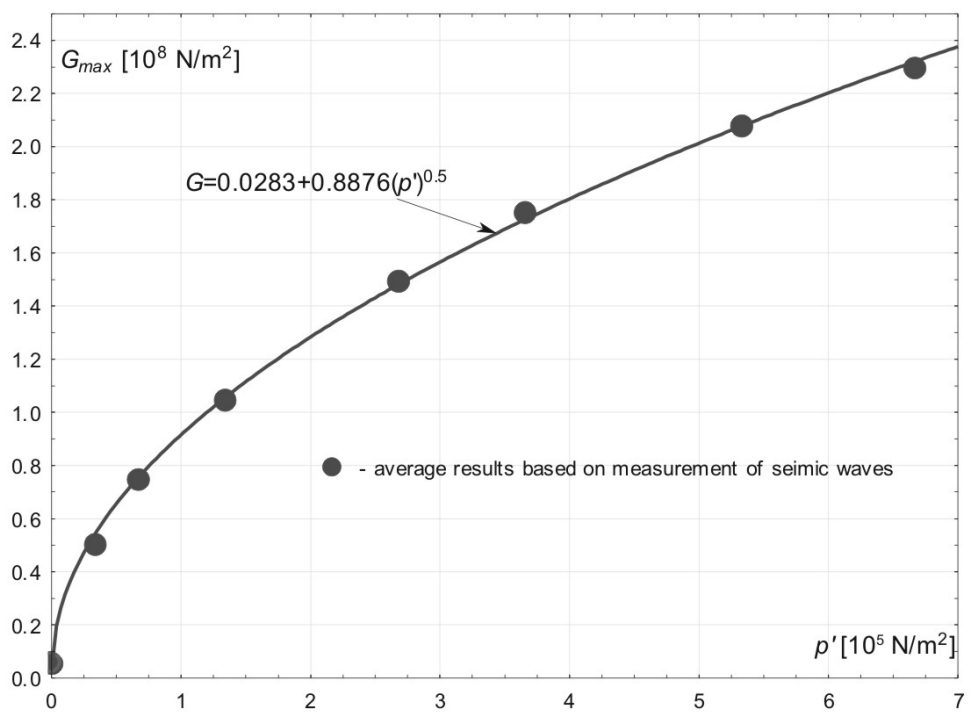

Fig. 3. Maximum shear modulus versus mean effective stress determined in terms of measured velocity of the seismic wave

Most". Near the dams surrounding the tailings deposits, the phreatic surface is located relatively low and controlled by an extensive drainage system. Going inwards, the phreatic surface rises gradually to the water pond level. In numerical simulations, it was assumed that a predominant portion of the tailings mass is fully saturated. The calculations were carried out for a $1 \mathrm{D}$ boundary value problem, which is the simplest, but also the extreme case. The same approach was applied to reproduce the liquefaction of a subsoil subjected to the earthquake which took place in the Kocaeli province, Turkey, in 1999 (Sawicki and Świdziński 2007).

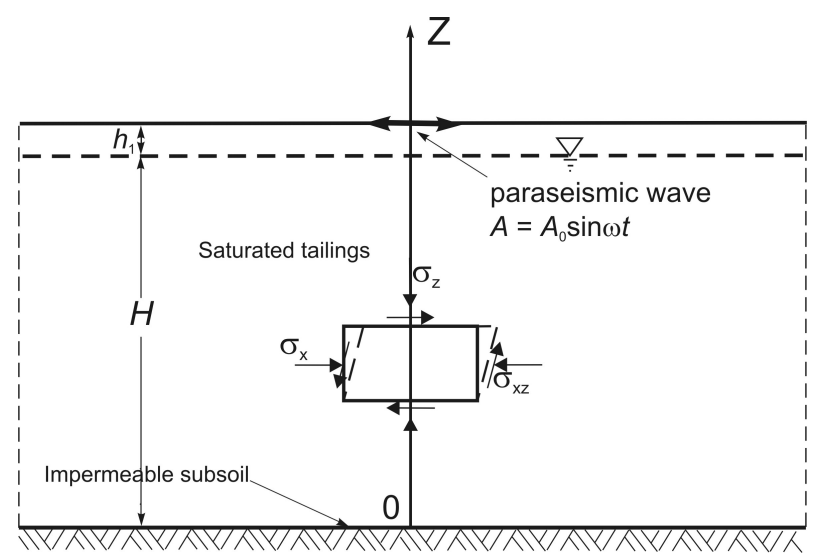

Fig. 4. Computational scheme for a saturated tailings mass subjected to seismic loading 
A generalized calculation scheme for a saturated tailings mass subjected to dynamic loading caused by a paraseismic event is shown in Fig. 4. It was assumed that the seismic loading is applied at the surface, which corresponds to the signal recorded by surface seismic stations at the TSF "Żelazny Most" dams and nearby.

For the sake of convenience, a non-dimensional variable corresponding to tailings thickness was assumed: $Z=z / H$, where $H$ is the thickness of saturated tailings.

Please note that, since the $\mathrm{C} / \mathrm{L}$ model has been formulated for amplitudes of cyclic loading, the equations used in the boundary value problem considered are formulated in terms of amplitudes, as well. Therefore, it is tacitly assumed that either the cyclic loading or the soil response are represented by harmonic functions.

For the one-dimensional case, the equation of motion and strain-stress relationship (4) lead to the following differential equation, which describes cyclic changes in the shear stress amplitude in the saturated soil stratum subjected to cyclic loading, see e.g. Sawicki and Świdziński (1989):

$$
\begin{aligned}
& \frac{d^{2} \tau_{0}}{d Z^{2}}+\frac{\zeta}{G} \tau_{0}=0, \\
& \zeta=\frac{\rho_{\text {sat }} \omega^{2} H^{2} \varepsilon_{0}}{\sigma_{0}},
\end{aligned}
$$

where $\rho_{\text {sat }}$ is the density of fully saturated soil and $\omega$ is the frequency of cyclic loading $(\omega=2 \pi / f)$. Appropriate boundary conditions are the following:

$$
\begin{gathered}
\tau_{0}(Z=1)=0, \\
\frac{d \tau_{0}}{d Z}(Z=1)=\frac{\rho_{s a t} H A_{0}}{\sigma_{0}} .
\end{gathered}
$$

For the 1D case, Eq. (6) describing the generation of pore water pressure due to cyclic loading, together with Eqs (1), (4) and (8), yields the following differential equation:

$$
\frac{d u}{d N}=\frac{D_{1} \tau_{0}^{2}}{4 a\left(G_{0}+G_{1} \sqrt{p_{0}^{\prime}-u}\right)^{2}} \exp \left(-D_{2} a u\right) .
$$

Equations (15)-(19) supplemented by Eqs. (5) and (8) make it possible to monitor the development of pore water pressure in a saturated subsoil subjected to cyclic loading. Please note that the generated pore pressure $u$ corresponds to the excess of pore pressure over the hydrostatic pressure in the soil mass.

The system of differential equations was solved numerically by the finite differences method according to the following algorithm. For initial conditions corresponding to the geostatic case $u=0$ and the shear modulus depending on the initial distribution of the mean effective stress $p_{0}^{\prime}$, solving Eq. (15) with boundary conditions (17) and (18) one obtains the initial distribution of the shear stress amplitude $\tau_{0}$ with depth. Next, for the calculated shear stress and the assumed increment of the loading cycle 
$\Delta N$, which is treated as a continuous variable, Eq. (19) is integrated, yielding a distribution of the generated pore water pressure $u$ with depth and consequently reduced $p^{\prime}$, see Eq. (8). Then, using Eq. (5), one calculates a new distribution of the shear modulus and thus a new distribution of $\tau_{0}$, solving again Eq. (15). The calculations are carried out until condition (8) is reached, which corresponds to local liquefaction at any discrete point in the soil mass.

Numerous convergence tests allowed for the optimal assumption of either layer discretization or the calculation time step.

\section{Results of Numerical Simulations}

Before assessing the liquefaction potential due to a real seismic event, several series of calculations were carried out to validate the model and the calculation algorithm assumed, as well as to verify the sensitivity of the model through a parametric study. The parametric study analysed the impact of the acceleration amplitude and the depth of the saturated zone within the tailings mass. Moreover, the influence of tailings permeability, contributing to the dissipation of pore water pressure parallel to its generation, was also considered.

The values of the parameters assumed for numerical calculations are the following: $H=40 \mathrm{~m}, \rho_{\text {sat }}=18.5 \mathrm{kN} / \mathrm{m}^{3}, n_{0}=0.46, K_{0}=0.5, f=2.1 \mathrm{~s}^{-1}, C_{1}=7.33$, $C_{2}=0.244, G_{0}=0.0283, G_{1}=0.8876, \kappa_{s}=0.75 \times 10^{-8} \mathrm{~m}^{2} / \mathrm{N}$.

\subsection{Pore Water Pressure Generation under Fully Undrained Conditions}

In this case, it was assumed that the generation of pore water pressure occurs under fully undrained conditions without any dissipation and the whole mass of tailings is saturated $\left(H_{1}=0\right.$, Fig. 4$)$. The calculations of pore water pressure build-up were made for a constant value of the horizontal acceleration amplitude of cyclic loading $A_{0}=0.1 \mathrm{~g}$, where $g$ denotes the acceleration of gravity. The development of pore water pressure as a function of loading cycles within the layer of saturated tailings is shown in Fig. 5.

One can notice that, due to seismic loading with a constant horizontal acceleration amplitude, one can expect a non-uniform generation of pore water pressure within the tailings mass, which may lead to liquefaction during the $41^{\text {st }}$ cycle of loading, which is equivalent to 20 seconds of loading duration.

Fig. 6, on the other hand, presents the development of pore water pressure at a depth of $3.5 \mathrm{~m}$ under the surface, where the liquefaction process was initiated, for various values of the horizontal acceleration amplitude ranging between $0.01 \mathrm{~g}$ and 0.19 .

It can be seen that liquefaction can be initiated within 100 cycles of seismic loading when the horizontal acceleration reaches $0.07 \mathrm{~g}$. For any higher value of $A_{0}$, liquefaction would start sooner, as shown in Fig. 7. 


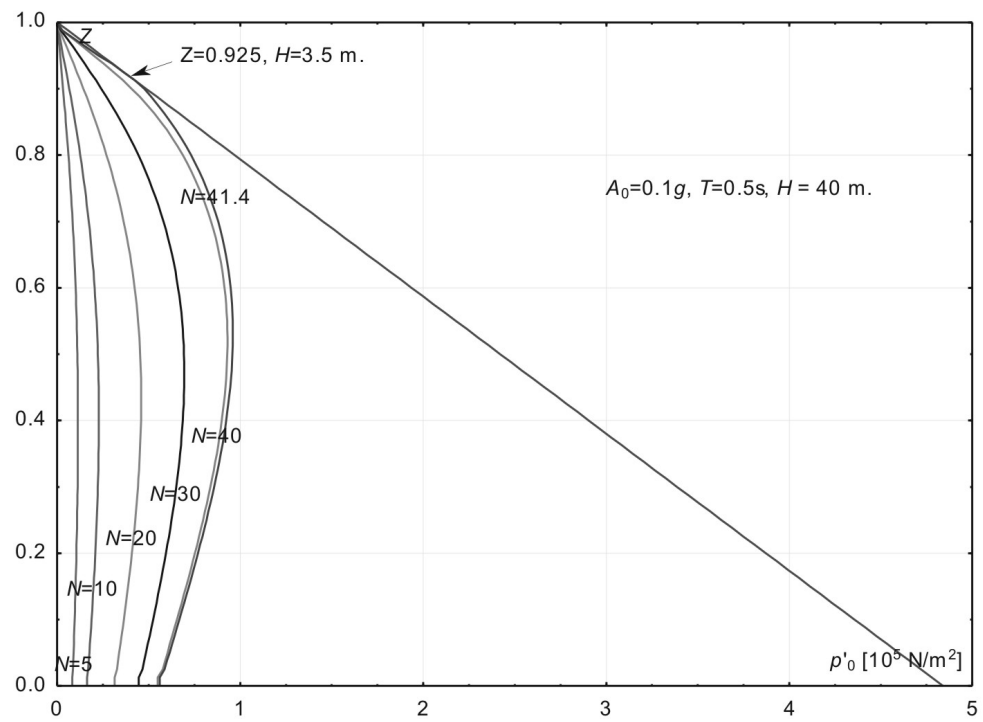

Fig. 5. Pore water pressure generation in the layer of saturated tailings subjected to cyclic loading with a constant value of the horizontal acceleration amplitude $A_{0}=0.1 \mathrm{~g}$

In the cases considered, it was assumed that the whole layer of tailings is fully saturated $\left(h_{1}=0\right.$, Fig. 4$)$, which means that the mean effective stress $p_{0}^{\prime}$ at the surface is zero. Fig. 8 shows the development of pore water pressure versus the number of loading cycles for the constant horizontal acceleration amplitude $A_{0}=0.1 \mathrm{~g}$ of the saturated tailings layer with the phreatic surface at a depth of $2 \mathrm{~m}$. It is seen that for a lower location of the phreatic surface more loading cycles $N_{L}$ are required to initiate liquefaction, and this process starts much deeper than it does in a layer of fully saturated tailings. In the latter case, when the phreatic surface was at the surface of the terrain, liquefaction began after 41 cycles at a depth of $3.5 \mathrm{~m}$ (see Fig. 4), whereas for $2 \mathrm{~m}$ of dry tailings over saturated ones 65 cycles were required and liquefaction took place at a depth of $11 \mathrm{~m}$.

The impact of the depth of the saturation line on the time of liquefaction initiation $\left(N_{L}\right)$ and the depth of its occurrence is presented in Fig. 9. It can be clearly seen that, for the horizontal acceleration amplitude $A_{0}=0.1 \mathrm{~g}$, liquefaction will not occur within 100 cycles of seismic loading if the phreatic surface in the tailings mass is located at a depth of $6 \mathrm{~m}$ or lower.

\subsection{Generation and Simultaneous Dissipation of Pore Water Pressure}

Under real conditions, a fully undrained state hardly ever occurs. In the case of tailings deposited artificially by spigotting at a TSF, one can observe a process of grain segregation leading to highly variable local permeability conditions with high permeability anisotropy. 


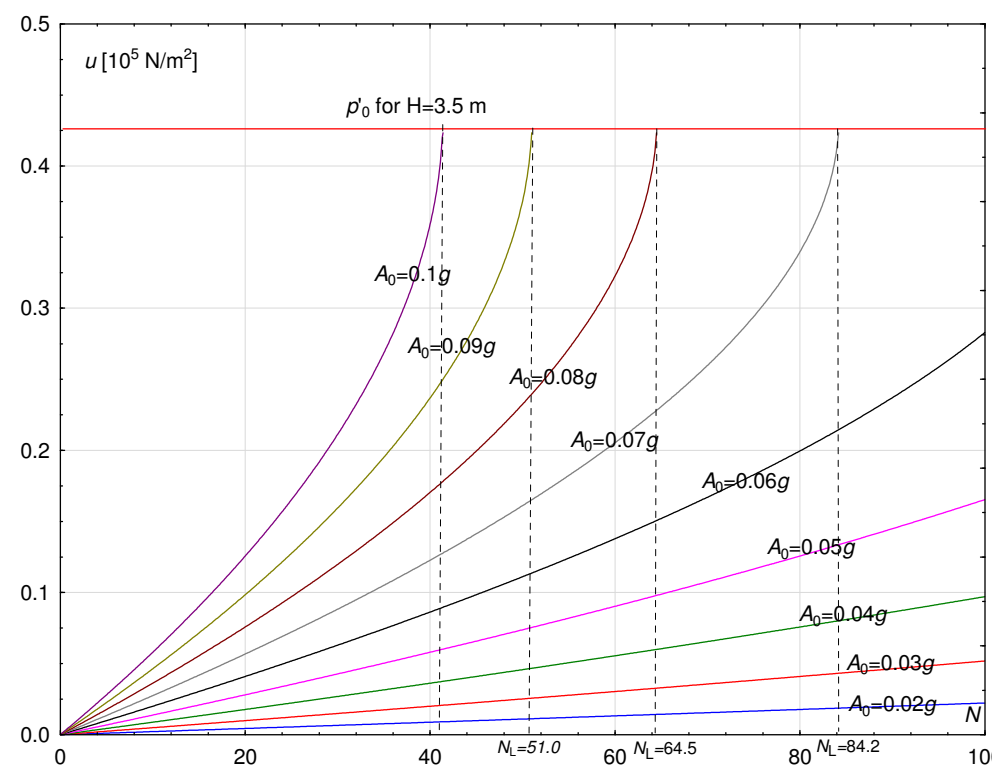

Fig. 6. Pore water pressure build-up in the saturated tailings layer at a depth of $3.5 \mathrm{~m}$ for various values of the horizontal acceleration amplitude

In order to verify the impact of the permeability of tailings on the rate of pore water pressure generation combined with simultaneous pore water pressure dissipation, the basic equations of the $\mathrm{C} / \mathrm{L}$ model were supplemented by an additional groundwater flow equation originally proposed by Verruijt (1969):

$$
\frac{k}{\gamma_{w} \kappa_{s}} \frac{\partial^{2} u}{\partial z^{2}}-\frac{\partial u}{\partial t}=0,
$$

where $k$ denotes a coefficient of permeability and $\gamma_{w}$ is the unit weight of water.

The equation of groundwater flow was supplemented by the respective boundary conditions at the bottom and the top of saturated tailings:

$$
\frac{\partial u}{\partial z}(z=0)=0, \quad u(z=H)=0 .
$$

Differential equation (20) was implemented in the numerical algorithm directly after Eq. (19) and solved using finite differences, as well. When pore water pressure is generated and simultaneously dissipated, the latter process starts immediately after an assumed portion of pore water pressure has been generated, say for a given cyclic increment $\Delta N$, and Eq. (20) is integrated. The distribution of pore water pressure after its generation during $\Delta N$ is the initial condition for the dissipation equation, and pressure dissipation is calculated within a time period corresponding to $\Delta N$. Subsequently, the distribution of pore pressure at the end of dissipation corresponds to the initial condition for further pressure generation, and so forth. 


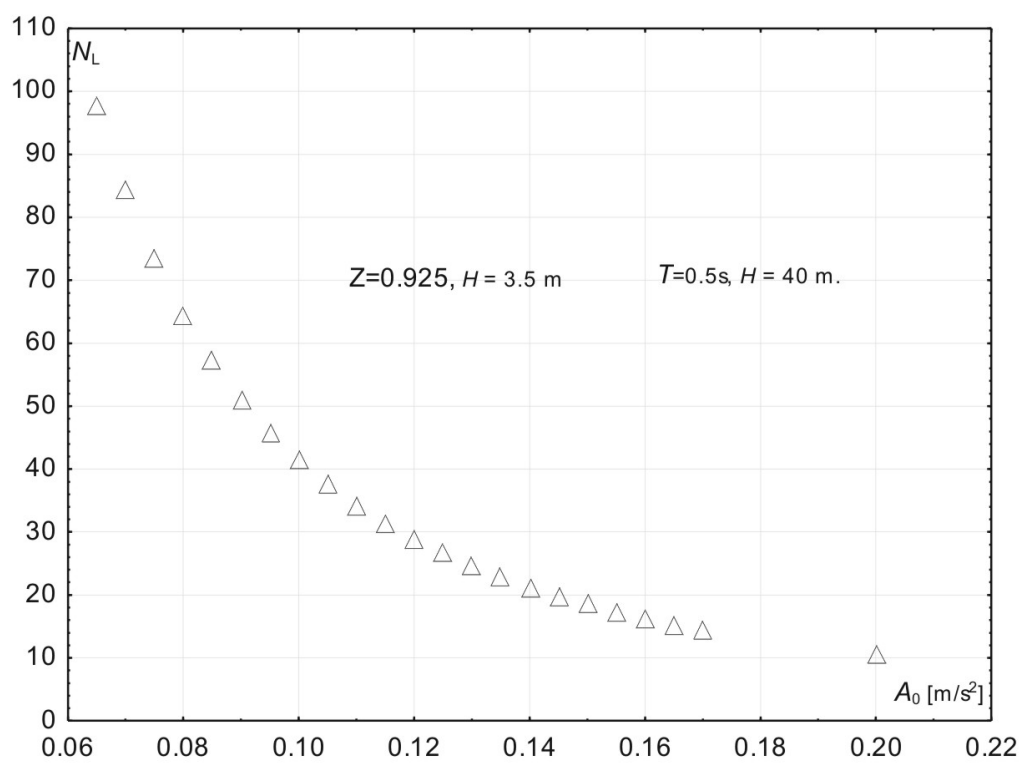

Fig. 7. Number of loading cycles to liquefaction versus the value of the horizontal acceleration amplitude

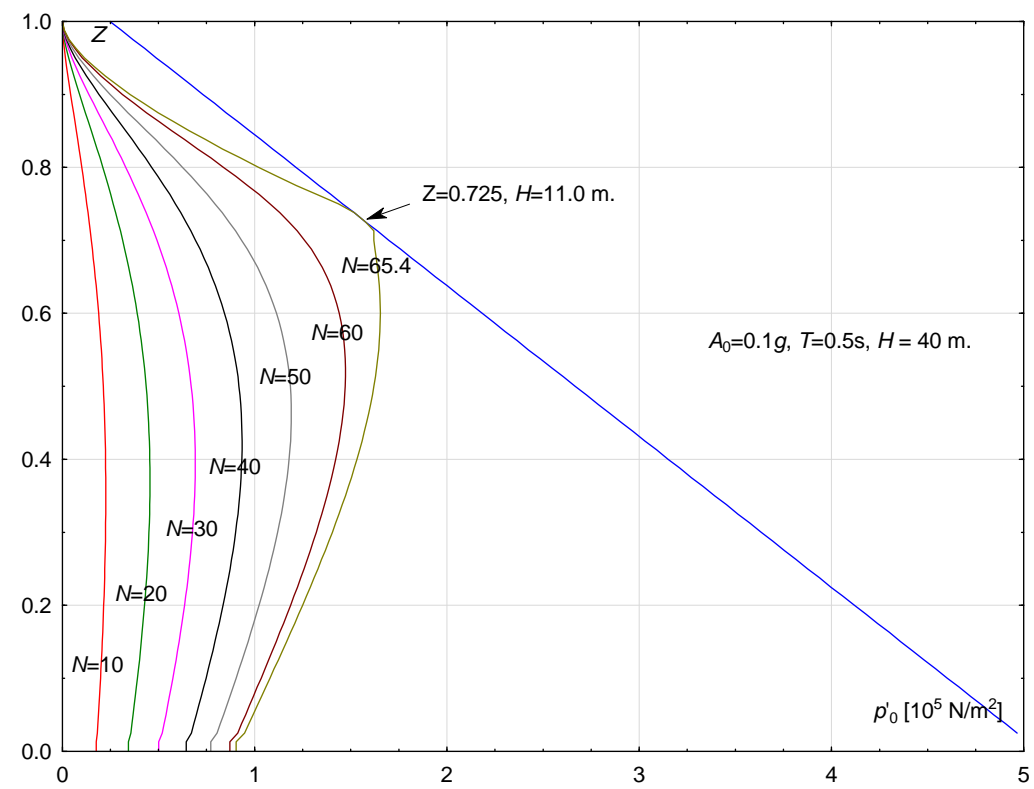

Fig. 8. Pore water pressure generation in a saturated tailings layer under a $2 \mathrm{~m}$ layer of dry tailings, subjected to seismic loading with the constant horizontal acceleration amplitude $A_{0}=0.1 g$ 


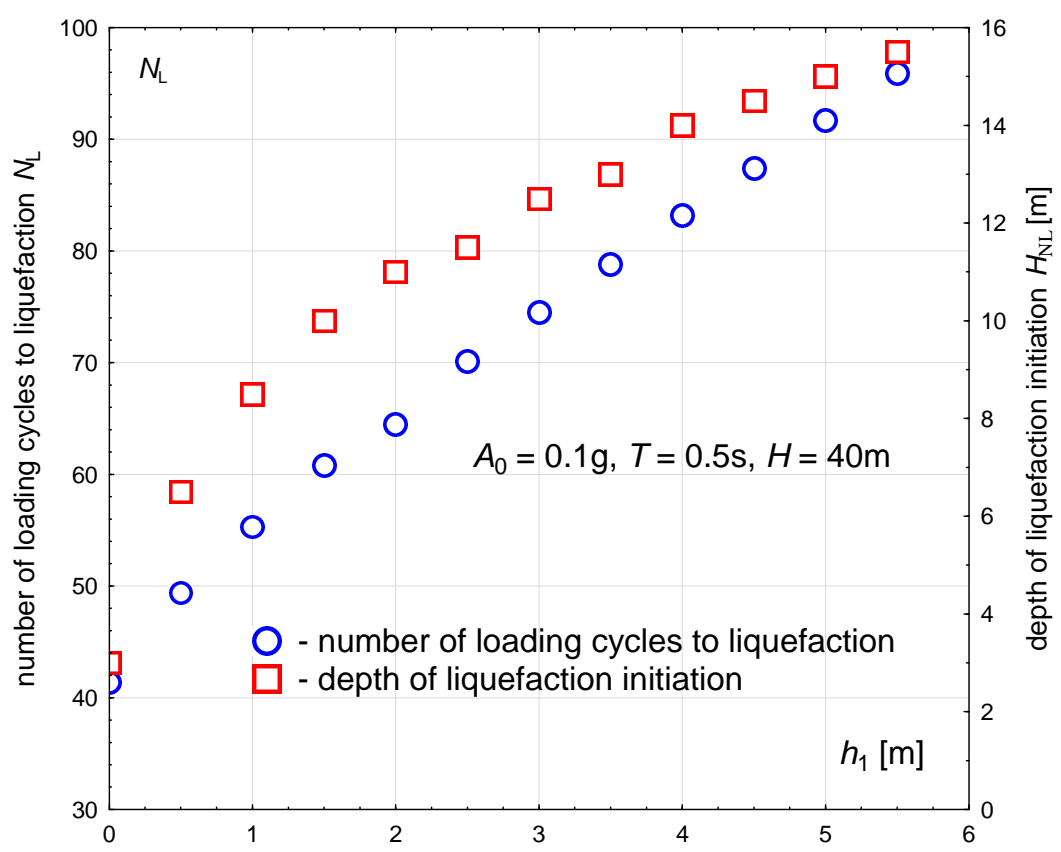

Fig. 9. Impact of the depth of the full saturation line on the time of liquefaction initiation $\left(N_{L}\right)$ and its depth $\left(H_{N L}\right)$

The impact of the dissipation process on the rate of pore water pressure generation is strongly dependent on the dissipative potential of a given soil medium, which is governed by its permeability. Fig. 10 shows the impact of the permeability of tailings on the number of loading cycles to liquefaction $N_{L}$. The calculations were again carried out for the same constant amplitude of horizontal acceleration $A_{0}=0.1 \mathrm{~g}$. It is seen that even for relatively coarse tailings characterized by a permeability coefficient of the order of $10^{-6} \mathrm{~m} / \mathrm{s}$, which are normally deposited near the dam crest, the dissipation process does not significantly impact the rate of pore water pressure generation. The impact is noticed at a permeability coefficient of $3 \times 10^{-4} \mathrm{~m} / \mathrm{s}$, which does not regard any type of tailings deposited at the TSF "Żelazny Most”.

Another reason for the small impact of dissipation on the rate of pore water pressure generation is the relatively short duration of dynamic loading, since the effectiveness of dissipation strongly depends on time, as well. Therefore, during natural earthquakes, liquefaction is observed even in coarse sands, which are characterized by very good permeability conditions.

\subsection{Response of Saturated Tailings to a Real Paraseismic Event}

In order to verify whether mining-induced paraseimic events recorded at the TSF "Żelazny Most" dams can trigger the liquefaction of saturated tailings deposited there, some additional numerical simulations were performed, assuming real paraseismic 


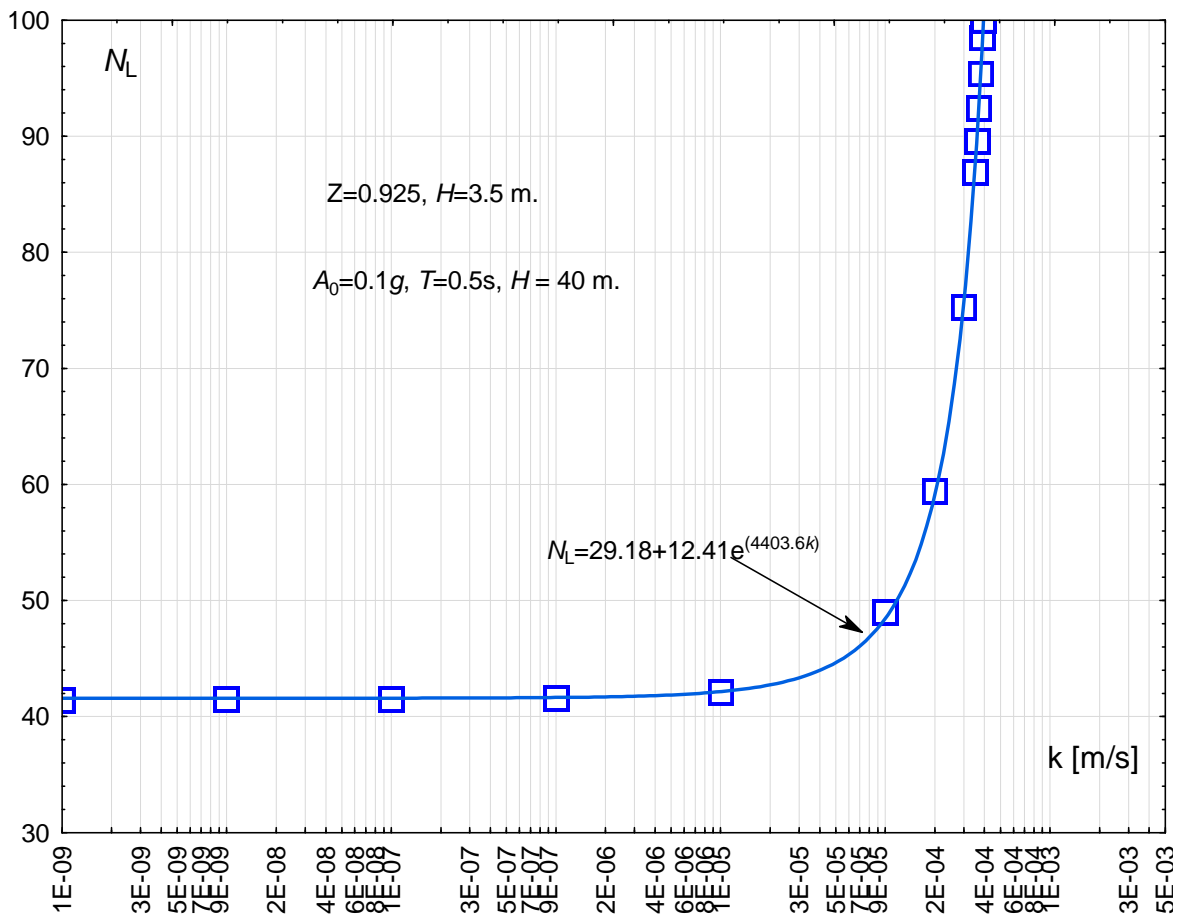

Fig. 10. Impact of the permeability coefficient $k$ on the number of loading cycles to liquefaction

loading. In the analysis, one of the strongest signals ever recorded at the TSF dams was assumed. This signal belonged to the so-called "medium" type of signals, which means that the epicentre was located not very close to the facility ("close" type) and not very far ("far" type). Particular types of signals differ in the horizontal component of peak ground acceleration (PGA) and Arias intensity $\left(I_{a}\right)$ (Arias 1970).

In numerical calculations, the originally recorded signal was subjected to low-pass filtering with a $10 \mathrm{~Hz}$ ultimate frequency, see Świdziński and Korzec (2013).

The accelerogram assumed for calculations is shown in Fig. 11 together with an amplitude envelope to be implemented in the $\mathrm{C} / \mathrm{L}$ model. The average period of the acceleration series is $T=0.22 \mathrm{~s}$, which corresponds to approximately 34 loading cycles, and only in a few of them the acceleration exceeds $0.04 \mathrm{~g}$. The Fourier spectrum of the accelerogram from Fig. 11, which has been subjected to a Fourier transform, is shown in Fig. 12.

The development of pore pressure caused by the paraseimic loading from Fig. 11 is presented in Fig. 13. Because of the very small level of pore pressures generated, the horizontal scale has been limited to small values, cf. Figs 5 and 8 . This means that the current paraseimic activity observed near the TSF "Żelazny Most" should not trigger any liquefaction process in saturated tailings deposited within the facility. 


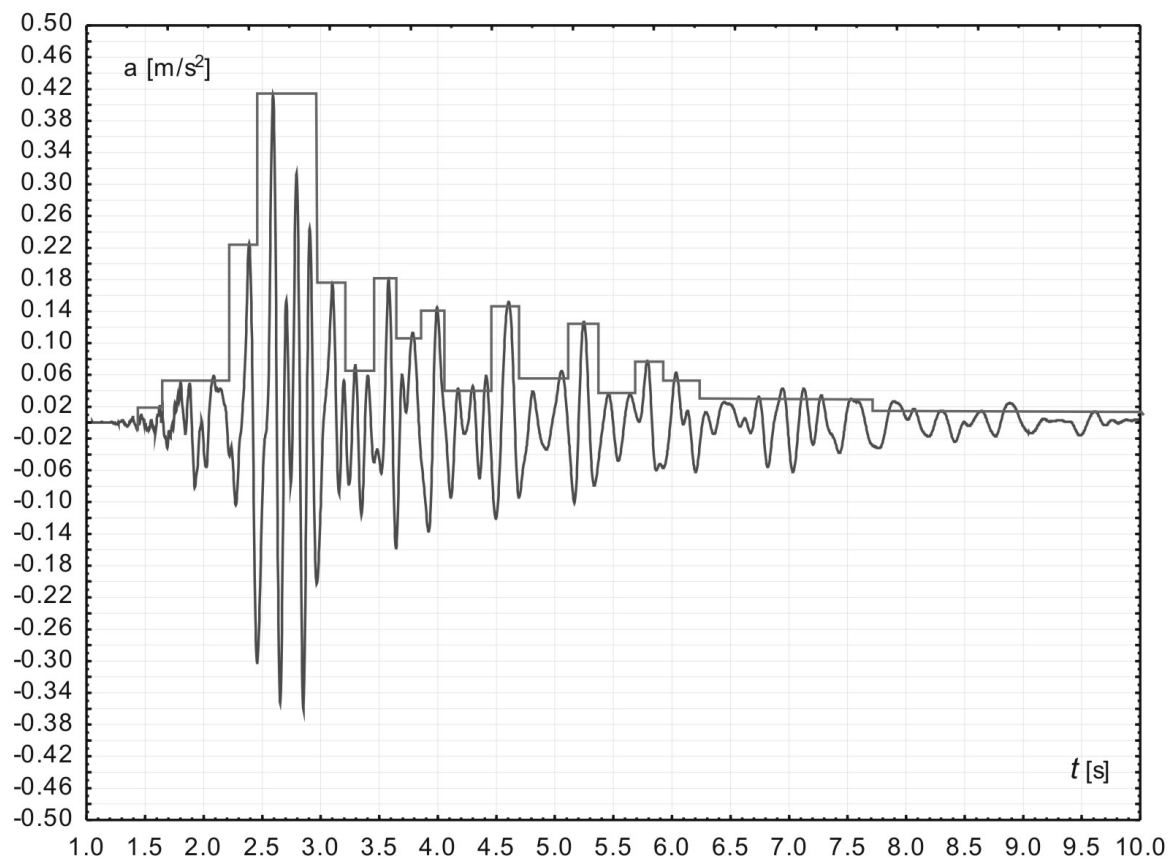

Fig. 11. One of the strongest accelerograms recorded on at the TSF "Żelazny Most" dams with an amplitude envelope

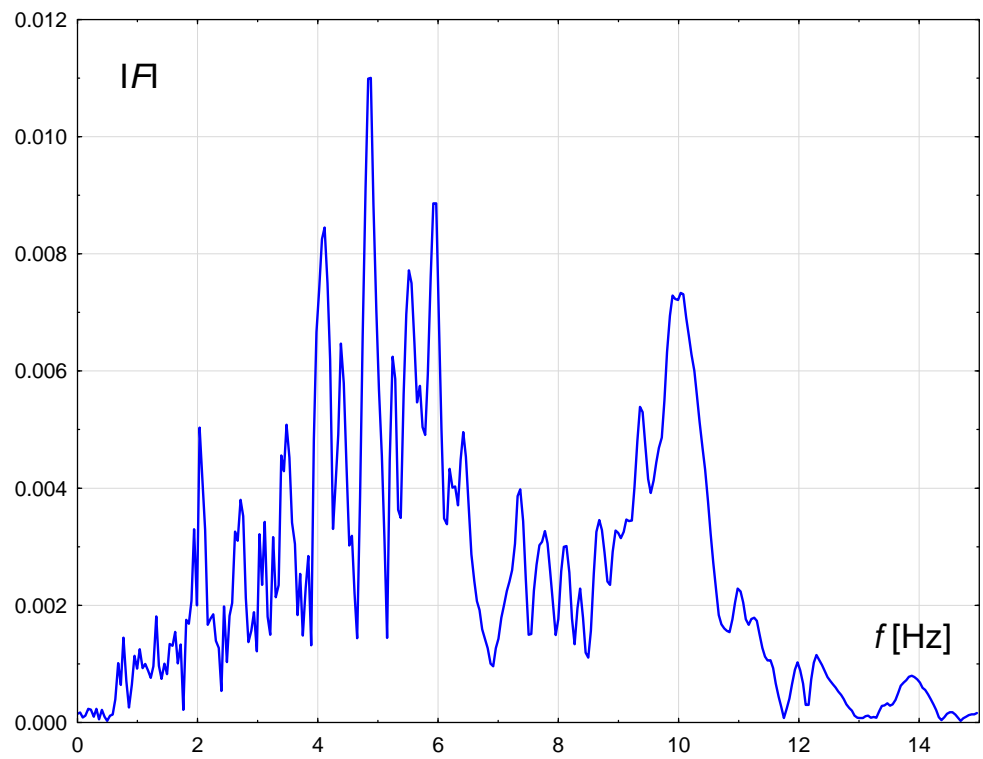

Fig. 12. Fourier spectrum of the accelerogram shown in Fig. 11 


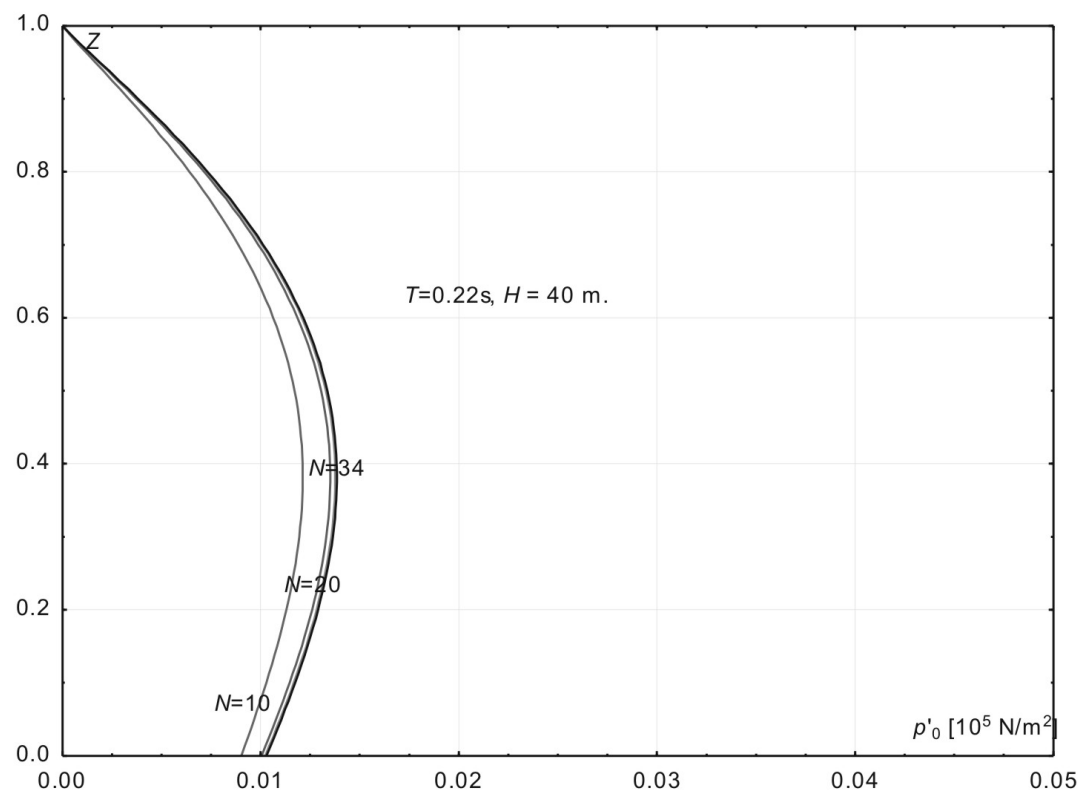

Fig. 13. Development of pore water pressure in saturated tailings at the TSF "Żelazny Most" due to the strongest paraseismic loading recorded nearby

\section{Summary}

The paper presents the implementation of the compaction/liquefaction $(\mathrm{C} / \mathrm{L})$ model to simulate the generation of pore water pressure up to the liquefaction of saturated post-flotation tailings due to dynamic loading induced by a paraseismic event. Originally, the $\mathrm{C} / \mathrm{L}$ model was elaborated for typical non-cohesive soils such as clean sands, whereas post-flotation tailings contain considerable portion of fine grains. However, both the results of laboratory tests and numerical simulations have proven that the $\mathrm{C} / \mathrm{L}$ model is also valid for this type of soils.

The model parameters and index properties were determined through series of laboratory tests carried out on samples of tailings from the TSF "Żelazny Most" in various apparatuses. The results of compactness in a cyclic simple shear device revealed that the model hypothesis of the existence of a common compaction curve for typical non-cohesive soils, which is one of the fundamental rules of the $\mathrm{C} / \mathrm{L}$ model, is also valid for tailings. The material coefficients determined on the basis on these tests were used to define the model compaction function for tailings.

The C/L model was applied to a one-dimensional boundary value problem in order to simulate the generation of pore water pressure up to liquefaction in a layer of saturated tailings subjected to paraseismic loading at various values of the horizontal acceleration amplitude. Some numerical tests showed that the level of pore water 
pressure generated is strongly dependent on this parameter, and liquefaction can be initiated only for relatively high accelerations.

The analysis of pore water pressure generation combined with simultaneous pore water pressure dissipation indicated that, due to the weak dissipation potential of tailings (relatively poor permeability conditions) as well as the short duration of dynamic loading, pore water pressure dissipation has practically no impact on the rate of pressure generation.

Moreover, the numerical tests revealed that, when full saturation line is located below the surface, the generation of pore water pressure is significantly delayed and the probability of liquefaction is greatly reduced.

According to numerical simulations for one of the strongest accelerograms ever recorded at the dams of the TSF "Żelazny Most", the pore water pressures generated are very low, which, for the seismicity currently recorded near that TSF, reduces the risk of tailings liquefaction practically to zero.

\section{References}

Arias A. (1970) A measure of earthquake intensity, [in:] R. J. Hansen (ed), Seismic Design for Nuclear Power Plants, The M.I.T. Press, 438-483 .

Boulanger R. W. and Idriss I. M. (2006) Liquefaction susceptibility criteria for silts and clays, J. Geotech. and Geoenvir. Engrg., ASCE, 132 (11), 1413-1426.

Dyvic R. and Madhus C. (1985) 'Measurements of $G_{\max }$ using bender elements, Civil Engrs Convention, Detroit, New York, American Society of Civil Engineers, 1985, 186-196.

PIANC (2001) Seismic Design Guidelines for Port Structures, Lisse/Abingdon/Exton (Pa)/Tokyo, Balkema.

Przewłócki J., Knabe W. (1995) Settlement of a soil stratum subjected to an earthquake, Int. Jnl. for Numerical and Analytical Methods in Geomechanics, 19, 813-821.

Sawicki A. (1987) An engineering model for compaction of sand under cyclic loading, Engieneering Transactions, 35 (4), 677-693 (in Polish).

Sawicki, A. (2004) Modelling earthquake-induced phenomena in the Izmit Bay coastal area, [in:] Th. Triantafyllidis (ed.) Cyclic Behaviour of Soils and Liquefaction Phenomena, Balkema, Leiden/London/New York/Philadelphia/Singapore, 431-440.

Sawicki A. and Świdziński W. (1989) Mechanics of a sandy subsoil subjected to cyclic loadings, Int. J. Numerical Analytical Methods in Geomechanics, 13, 511-529.

Sawicki A. and Świdziński W. (2007) A simple mathematical model for assessment of seismic-induced liquefaction of soils, J. Waterway, Port, Coastal and Ocean Engineering ASCE, LIMAS Special Issue, 133 (1), 50-54.

Seed H. D. and Idriss I. M (1970) Soil moduli and damping factors for dynamic response analysis, Rep. No. EERC 70-10, Earthquake Engrg. Res. Ctr., Univ. Of California, Berkley, Calif.

Świdziński W. (2006) Mechanisms of compaction and liquefaction of non-cohesive soils, IBW PAN Publishing House, pp. 245 (in Polish).

Świdziński W., (2011) Instability of post-flotation tailings reservoirs caused by static liquefaction, IBW PAN Internal Report (in Polish).

Świdziński W. and Korzec A. (2013) Implementation of simplified Newmark's approach and FEM dynamic analysis for Eurocode 8 based design of OUOW Żelazny Most storage facility, Report for 2013, Internal report for O/ZH KGHM POLSKA MIEDŹ S.A. (in Polish). 
Świdziński W. and Mierczyński J. (2010) Investigations of elastic response of non-cohesive soils by the measurement of seismic wave velocity, Wydawnictwo Techniczne Politechniki Krakowskiej, 1-Ś, 2010, ZESZYT 16, ROK 107, 63-82 (in Polish).

Świdziński W. and Mierczyński J. (2012) Laboratory Investigations Report, Internal Report for O/ZH KGHM POLSKA MIEDŹ S.A. (in Polish).

Verruijt A. (1969) Elastic storage in aquifers, [in:] R. J. M. De Wiest (ed.) Flow through Porous Media, New York: Academic Press, 331-376.

Yamamuro J. A. and Covert K. M. (2001) Monotonic and cyclic liquefaction of very loose sands with high silt content, J. Geotech. and Geoenvir. Engrg., ASCE, 127 (4), 314-324. 